\title{
Social Media and Knowledge Management: A Perfect Couple
}

\author{
Remko Helms, Jocelyn Cranefield, and Jurriaan van Reijsen
}

\section{Introduction}

With the emergence of Social Media there is a revival going on in Knowledge Management that is bringing new and exciting research directions along with it. The combination of Social Media and Knowledge Management is referred to as Social Knowledge Management and is the main theme of this book. Social Media emerged in the early 2000s, with platforms such as Wikipedia and SixDregrees. com, and "employ mobile and web-based technologies to create highly interactive platforms via which individuals and communities share, co-create, discuss, and modify user-generated content" (Kietzmann, Hermkens, McCarthy, \& Silvestre, 2011). Knowledge management and social media seem to be made for each other because social media platforms support sharing, co-creation and discussion which are key knowledge processes (von Krogh, 2012). Furthermore, the platforms are easy to use and they are available as software-as-a-service (SaaS), so there is no need for implementing and maintaining them. Initially, these technologies were mainly used by individuals that stayed in touch with their friends, for example, via Facebook; or shared their passion and expertise about fashion on their weblog. But due to a trend that is known as 'consumerization of IT', these kinds of technologies

R. Helms $(\bowtie)$

Faculty of Management, Science and Technology, Open University, Heerlen, The Netherlands e-mail: remko.helms@ou.nl

J. Cranefield

School of Information Management, Victoria University of Wellington, Wellington, New Zealand e-mail: Jocelyn.Cranefield@vuw.ac.nz

J. van Reijsen

The Courseware Company, Utrecht, The Netherlands

e-mail: vanreijsen@courseware.nl 
were also suddenly introduced into organizations (Niehaves, Köffer, \& Ortbach, 2012). For example, employees can easily start a discussion group on Yammer to serve their need for sharing knowledge and they can do this without assistance of the organization's IT department. The unique features of social media that coincide with the central knowledge processes and the bottom-up adoption of these technologies, are in our view key ingredients for a revival of knowledge management in organizations. To better understand this let us look back, in fast forward mode, at how knowledge management evolved over time.

\section{Emergence of Knowledge Management Discipline}

Knowledge Management is something that organizations have been doing since the first organizations started to emerge (Hansen, Nohria, \& Tierney, 1999). A famous Dutch example in this respect is how the Dutch East India Company codified and protected knowledge. In the 1600s, the Dutch were very successful in spice trade with the East (Indonesia amongst other countries) and the organization controlling this trade was the Dutch East India Company. For a safe and fast passage to the East, knowledge of the best routes was essential, so the Dutch East India Company documented this knowledge on maps. The company was well-known for high quality maps indicating coasts, harbors, tide tables, ocean streams and other useful information. These maps were considered intellectual property by the company and were therefore not shared with its rivals, such as the British and the Portuguese (De VOC site, n.d.). Officers on the ships were even instructed to destroy the maps in the event of the ship being attacked by rivals. This practice by the Dutch East India Company can be considered as a form of knowledge management, although the term did not yet exist.

Some centuries later, the term knowledge management was introduced for such practices. The emergence of knowledge management can be related to two important trends: the rise of the knowledge-based perspective of the firm (Grant, 1996) and developments in computer and network technology (Hansen et al., 1999) in the early 1990s. The knowledge-based perspective is the successor of the resourcebased view of the firm (Barney, 1991) and acknowledges that knowledge is the most important resource of organizations for value creation. This gave rise to the idea that practices and methods were needed to manage and protect that knowledge. On the other hand, computer and network technology made it possible to codify knowledge and quickly disseminate it through the organization because computers were connected to each other in a network. The practices and methods to manage knowledge processes became known as knowledge management, while the computer and network technology supporting knowledge management were referred to as knowledge management systems (Alavi \& Leidner, 2001). 


\section{$3 \quad$ Struggling to Keep Knowledge Management on the Strategic Agenda}

Since the 1990s, organizations have been implementing knowledge management practices, methods and techniques in order to enable and support knowledge processes including the creation, acquisition, storage, sharing and application of knowledge (Heisig, 2009). After a rapid early uptake in the 1990s, it seems that organizations lost interest in knowledge management in the period that followed. A possible explanation is that traditional knowledge management implementations are expensive and do not always meet expectations (Chua \& Lam, 2005; Malhotra, 2005). This is illustrated by research from Huysman and de Wit (2004) who describe how knowledge management implementations fail when organizations get into the ICT, management or local learning trap. They claim that this is a typical problem of 'first wave' knowledge management that is focused on the so called codification approach (Hansen et al., 1999). In this approach the focus is on knowledge as an object that needs to be stored and managed (Alavi \& Leidner, 2001). Huysman and de Wit (2004) argue that organizations can overcome the problems of 'first wave' knowledge management by combining the codification approach with a socialization approach and taking a more bottom-up oriented adoption approach towards knowledge management that they call 'second wave' knowledge management. The socialization approach acknowledges that knowledge is embodied in people, i.e. tacit knowledge, and is inherently difficult to codify (Hansen et al., 1999; Polanyi, 1967). This approach aims at connecting people, thus enabling them to share their tacit knowledge with others through social interaction. Classic examples of knowledge management practices that rely on socialization are communities of practice and knowledge networks (Back et al., 2005; Helms \& Buysrogge, 2006; Wenger \& Snyder, 2000). Furthermore, the bottom-up approach suggests that knowledge management practices should not be enforced on employees by management, and rather that employees should be empowered and enabled to manage their own knowledge (Huysman \& de Wit, 2004).

\section{$4 \quad$ Social Media Is Re-energizing Knowledge Management}

Social media technologies seem to be a perfect match with the focus on socialization and the bottom-up approach in second wave knowledge management. Two core concepts underlying social media technology are communities and networking; concepts that are also central in the socialization approach to knowledge management. Furthermore, these technologies support a bottom-up approach towards knowledge management in organizations. Initially used privately by individual users to connect and interact with friends and family, these technologies soon entered the workplace due to trends such as Bring Your Own Device (BYOD) and the consumerization of IT (Niehaves et al., 2012). Now, anyone with a smartphone or tablet can start a group on Yammer or Google Groups, and invite colleagues to discuss work-related matters. Such bottom-up initiatives for knowledge sharing 
characterize the potential of social media to support knowledge management in organizations. However, social media technology is not just one technology but a mix of different technologies including social networking, wikis, (micro)blogs, social bookmarking and media sharing platforms (Bebensee, Helms, \& Spruit, 2011). Each technology has its own distinctive characteristics and can support knowledge management in different ways (Majchrzak, Faraj, Kane, \& Azad, 2013).

\subsection{Social Networking}

Social networking technologies are the most well-known social media. Today, Facebook is by far the largest social network with more than 1.6 billion active monthly users (Facebook, n.d.); more than the population of China, the world's most populous country. On social network sites, users can build a profile, connect to others and keep their friends updated using posts (Boyd \& Ellison, 2007). These tools support people in establishing and maintaining online relationships with each other. Some social networks have a specific focus, such as LinkedIn, which aims at establishing and maintaining professional relationships. The resulting social fabric is often referred to as the social capital of employees (Tsai \& Ghoshal, 1998). In a knowledge management context, profiles on social networks can be used to document one's skills and experiences. The relations form a network that enables employees to find others with relevant expertise. Therefore, a social network can function as an expertise locator (Maybury, 2002; Rivera-pelayo et al., 2013). This function is further strengthened by the fact that users can also post messages, which enables them to share and discuss ideas but also to respond to questions. These messages help in building a reputation online that confirms the expertise of a person. However, the content on social networks is highly volatile and not wellstructured. Hence, it is difficult to search and find past discussions for example.

\subsection{Blogging}

Blogs (weblogs) provide users with a platform to publish their ideas and stories directly online to a worldwide audience (Du \& Wagner, 2006). Others can comment on these blog posts directly or link to a particular blog post from their own blog. Blogs are used for both private and business purposes. Examples include tech blogs that report on the latest technology and fashion blogs that follow fashion trends. Starting a blog is relatively easy: a user can sign up with a platform such as WordPress, set up a blog in minutes and start sharing stories with the outside world. In contrast to social networks, blogs allow users to share longer pieces of content, including opinions, new ideas, experiences and findings. Furthermore, people blogging on the same topic can respond to each other's content and link to other blogs, thus creating an online community of people with the same interest. Therefore, blogs are also useful in supporting knowledge creation and developing shared practices inside the organization (Kaiser, Kansy, Mueller-Seitz, \& Ringlstetter, 
2009). The connected blogs, together with the people and procedures that update this knowledge, can be seen as constituting a transactive memory system (Nevo, Benbasat, \& Wand, 2012; Wegner, 1987).

\subsection{Wikis}

Wikis have become famous through Wikipedia, the best-known wiki in the world. A wiki consists of a number of hyperlinked text documents. A powerful feature of wikis is that they allow users to collaboratively work on documents and to provide feedback on new content and changes made by others (Wagner, 2004). A key aspect of their success lies in the fact that wikis rely on the wisdom of the crowd rather than on the wisdom of a single expert (Niederer \& van Dijck, 2010). Wikis can be used for different purposes and while Wikipedia is a user-generated and managed encyclopedia, it can be used for many different purposes. In an organizational context a wiki can, for example, be used to document and improve work processes (Majchrzak, Wagner, \& Yates, 2006). People can collaboratively work on process descriptions and when processes change, these process descriptions can be easily changed and peer reviewed by colleagues. Furthermore, people who are unfamiliar with the processes can consult the wiki to learn about them. Wikis can also be used to codify and share critical knowledge in the organization. Software companies are, for example, using wikis to store and share knowledge about the products they develop, such as architectural decisions and technical issues (Bibbo, Sprehe, Michelich, \& Lee, 2010; Paasivaara \& Lassenius, 2014). Furthermore, a wiki is not necessarily restricted to the organizational boundaries. It is also possible to open up the wiki to the outside world and to truly harness the benefits of the wisdom of the crowd. Take, for example, the idea of open innovation (Chesbrough, 2003), which states that the organization should leverage knowledge from outside the organization to be more innovative. A possible risk is the claimed inaccuracy of wisdom of the crowd (Chai, Potdar, \& Dillon, 2009). Wikis rely on peer-review mechanisms that should remove or correct faulty content, but if this malfunctions, it could lead to unreliable knowledge contributions.

\subsection{Social Bookmarking}

Social bookmarking systems enable users to attach keywords (i.e. tags) to resources that they post (Doerfel, Jäschke, \& Stumme, 2016), such as links to a web browser, documents, photos, videos and even tweets on Twitter (i.e. hashtags). Sharing of these resources amongst a wider group of users enables users to find resources based on the tags that they are interested in. For example, one user may bookmark Google.com as 'search engine' and another may bookmark AllTheWeb.com as 'search engine'. By exploring the 'search engine' tag, users can discover search engines that were previously unknown to them. Social bookmarking can support knowledge sharing in organizations but perhaps more significantly, it also supports 
knowledge discovery. Through social bookmarking, users might find interesting resources from people who are not in their direct personal network, hence spurring new ideas and innovation (Gray, 2011). Like other social media, social bookmarking began as publicly available tools geared at individual use, then later found its way into the organization. This is demonstrated by Dogear and NBC Universal (Bibbo et al., 2010; Millen, Feinberg, \& Kerr, 2006), which have employed social bookmarking for internal knowledge sharing, expertise location and support of communities of practice (Millen et al., 2006).

\subsection{Media Sharing}

Media sharing platforms focus on sharing media of a particular type, such as video (e.g. YouTube) or pictures (e.g. Instagram or Pinterest). Widely known for their use in entertainment and marketing, these platform can also be used for knowledge sharing, as exhibited by the myriad of "How to ..." videos that are posted online. For example, a 'how to' video about extending the memory of a laptop ${ }^{1}$ allows an experienced user to demonstrate how to replace memory to novice users who want to learn how to do this. Similarly in the corporate domain, YouTube has been used to share knowledge. For example, software engineers use YouTube clips to explain their code to each other (MacLeod, Storey, \& Bergen, 2015). Users can react to such videos by posting comments on the videos, resulting in online discussions which may result in new, improved videos. Furthermore, video and picture sharing can also be used for problem-solving purposes. Imagine a service technician for copying machines. When the technician encounters an unknown problem with a machine, he or she can make a video or take a picture and share it with fellow technicians. They might have encountered the problem before and can offer a solution to the problem at hand.

Yet another application of YouTube in organizations is for internal training purposes, for example, videos may be used to teach trainees about the organization or how to manage a project. These examples demonstrate that media sharing can support knowledge management in various ways, varying from knowledge sharing to problem-solving and learning. These tools can be more powerful than traditional text-based tool, because, as the famous saying goes, a picture can tell more than a thousand words. Furthermore, anyone can take pictures and videos anywhere, since modern smartphones and tablets have functionality supporting this.

\footnotetext{
${ }^{1}$ https://www.youtube.com/watch?v=L7FvZ-JduRM.
} 


\section{Beyond the Codification and Socialization Approach}

The above discussion on social media tools shows how these tools can be used to support different knowledge processes, such as knowledge creation and knowledge sharing. We began by saying that these technologies typically support the socialization approach to managing knowledge, aiming at connecting people and supporting discussion, collaboration and knowledge sharing. However, at the same time, they support the codification approach, because both content and interaction history is digitally captured by social media. Hence, social media are also valuable knowledge repositories that store knowledge for later re-use; for example, the videos stored on YouTube and the knowledge captured in a wiki. In order to support knowledge retrieval, it is important that these tools provide easy access to stored content. Furthermore, the digital traces and content of users on social media also offer an opportunity to generate new knowledge and insights by applying data mining techniques (Behrendt, Richter, \& Riemer, 2014). One such application is to recommend content and people to users of an organizational wiki (Leonardi, Huysman, \& Steinfield, 2013). An algorithm can be used to find pages that are often consulted together; for example, pages $\mathrm{X}$ and $\mathrm{Y}$. As a result, users who are consulting page $\mathrm{X}$ are sent a recommendation to also consult page Y. Another application of social media is to identify communities of interest in the organization based on the connections and interactions between users of social network sites. Clustering algorithms can be used here to find groups of people that have more connections to each other than to others in the network (Zygmunt, Brodka, Kazienko, \& Kozlak, 2012). Analyzing the groupings can reveal unidentified communities of interest in the organization. Applying social network analysis can also provide information on the central people in the network (i.e. potential experts) and the boundary spanners in organizations (Helms, 2007). Additionally, text mining can be applied to the messages between people using the social network site. Classification techniques can reveal what people are talking about, providing insight into the topics discussed (e.g. leisure or business) and also into how the site is used (e.g. information sharing or problem solving). Last, but not least, text mining and classification can be applied to networks with which technicians are collaboratively solving problems. Analyzing these text messages might reveal that certain problems always occur at particular places and/or contexts.

\subsection{Digital Traces on Social Media a Source of Knowledge}

This use of data is also referred to as a new approach for knowledge management called the 'sensor' approach (Newell, 2014). It is based on implicit knowledge sharing rather than explicit knowledge sharing because it uses the digital trails that are left behind when people are using social media. These users do not intentionally leave these trails because their main goal is to solve an immediate problem or to share information. However, in the process, implicit knowledge is generated that is of value for exploration. This implicit knowledge includes not only who is talking 
to whom and about what, but also information about the device that is being used and the location where it is used. It is believed that this sensor approach provides new opportunities for knowledge management and complements the codification and socialization approaches (Newell, 2014). The sensor approach coincides with the current big data trend and turns the data that is generated by users on social media in useful insights and knowledge.

\subsection{Introducing the Crowd to Organizational Knowledge Management}

A further development in knowledge management that has been driven by social media is the so-called 'crowd' approach to managing knowledge (Newell, 2014). This is based on employing the 'wisdom of the crowd' discussed above in relationship to wikis. Social media are not necessarily used within an organization. The fact that they are web-based and easy to use makes it possible to extend their use to people outside the organization. This enables organizations to leverage the knowledge of people outside company borders (von Krogh, 2012), such as experts at other organization (for example, universities), users of the organization's products and services, and outsiders who could be not be otherwise identified. With this new approach come two fundamental challenges that have been identified by von Krogh (2012). The first is the problem of knowledge spill-over outside the organization's boundaries. Traditionally, organizations have protected their knowledge since it is a valuable resource that can provide competitive advantage. When using social media, there is a risk that proprietary knowledge could be spilled-over because it is accidentally shared with those outside the organization. A second, complementary, problem is the risk of watering down the organization's proprietary knowledge. This problem emerges because social media make it very easy to consult knowledge outside the organizational boundary. Hence, employees might overlook proprietary knowledge from organizational knowledge repositories and instead use knowledge from publicly available resources that are also available to the competition. Worse still, unreliable knowledge may find its way into the organizational knowledge repositories. Either way, this has potential to undermine the strategic position of the organization.

\subsection{Complementary Approaches to Knowledge Management}

We stress that the four approaches to knowledge management that we have discussedcodification, socialization, sensor and crowd-should be not considered as separate choices, but as complementary approaches that have potential to mutually strengthen each other, whether used to support an organization's business strategy or to address a societal knowledge issue. The social media technologies available in the early twentyfirst century offer a range of diverse solutions to support these knowledge management approaches, with many more solutions yet to be discovered. Of course, social media is 
no silver bullet, and its relatively recent arrival presents new challenges that must be considered before organizations can successfully apply the new knowledge management approaches.

\section{Social Knowledge Management in Action: Book Overview}

This book aims to support organizations and scholars alike by providing an overview of new and innovative applications of social media for knowledge management and reporting on the facilitators of success, as well as the challenges, risks and issues that need to be tackled in applying social media in organizational contexts.

The first section of the book (Chaps. 2 and 3) present the current state of understanding about enterprise social networks (ESNs), with a focus on how they can support knowledge management and the nature of potential benefits for organizations. In Chap. 2, Enterprise Social Networks (ESNs) as platforms for Enabling and Understanding Knowledge Work, Janine Hacker provides a summary of the foundations underlying social knowledge management, identifying two major ways in which ESNs provide a potential source of value for managing knowledge work in contemporary organizations: Hacker reminds us that any attempt to manage knowledge must begin by considering the meaning of what constitutes knowledge. Whereas many traditional knowledge management approaches are based on the "possession view" of knowledge, social knowledge management originates from an alternative, "practice-oriented" perspective that views knowledge as being based in the doing of work and the accompanying social relationships. The consequent knowledge management focus arising from this perspective is on managing knowledge workmanaging the doing of knowledge rather than the having of knowledge. According to this practice-oriented view, ESNs provide potent value to organizations in two key ways: (1) they can help develop enabling contexts and (2) they can contribute to a better understanding of knowledge processes.

In Chap. 3, Mohammadbashir Sedighi and Mohammad T. Isaai consider the deeper, motivational reasons that lead to knowledge sharing benefits when knowledge management is based on enterprise social media. Based on an analysis of prior research, they elicit a rich understanding the reasons why ESNs can make a transformational, positive difference to knowledge sharing. They argue that that three essential properties of ESM systems - their entirety, visibility and informality-support certain perceived benefits of knowledge sharing while diminishing other perceived costs, thus significantly influencing employees' motivation for knowledge sharing, which leads to sustained participation. The authors combine their insights into an model to explain the impact of knowledge sharing behaviors.

Translating an organizational vision for an information system into a real-world success is a perennial challenge for managers and researchers alike. History has shown that regardless of the technology involved, there is no ready-made success formula, and that multiple interwoven issues are involved. Delivering on the promise of enterprise social KM is unlikely to prove an exception. The implementation of social networking in the enterprise presents both novel and familiar challenges: 
Key questions that face mangers include, what kind of Web 2.0 tools are suitable for which knowledge management purposes?, How should Web 2.0 be implemented? (Is a bottom-up or a top-down approach more suitable?); and what skills do knowledge workers need to effectively integrate Web 2.0 tools into their day-to-day work in the organization? The ways in which these practical concerns are addressed will inevitably impact on the outcome of ESN knowledge management efforts. The central section of the book (Chaps. 4-6) presents research that aims to address such practical questions, and draws implications for organizations, managers, and researchers.

In Chap. 4 Everist Limaj and Edward Bernroider report on an exploratory study in which they investigate which kind of social information and communication systems (SICS) are most suitable for supporting each of two key stages of knowledge transfer: knowledge acquisition and knowledge assimilation. Based on their findings, arising from pair-wise tool comparisons by experts, they draw conclusions about the relative importance of different tools for developing an organization's potential absorptive capacity.

Chapters 5 and 6 feature field-based research into enterprise social network implementations, considering issues to do with leadership of SKM implementation and the skills required for knowledge workers to make effective use of social KM systems. In Chap. 5, Ettore Bolisani and Enrico Scarso consider the issues associated with top-down versus bottom-up implementation and the resulting dichotomy facing managers. Their focus is the implementation approach for Web 2.0 in small and micro firms and leadership issues.

Chapter 6 explores the skills that are required at an individual level to integrate the use of Web 2.0 effectively into personal knowledge work within an organization. Rouhollah Fathizargaran and Jocelyn Cranefield present research into the implications of Web 2.0 for Personal Knowledge Management. Based on interviews with professionals in a multinational software engineering company they propose a framework of eight skills for PKM effectiveness in the context of Web 2.0 use.

The final two chapters of the book move the reader into new frontiers to explore the larger potential of social knowledge management for organizations and society. Both chapters propose visions for ways in which social media-based tools could be formally exploited to create beneficial insights and knowledge.

In Chap. 7, Janine Hacker, Rebecca Bernsmann and Kai Riemer explore metrics and dimensions of user behaviour in Enterprise Social Networks. The study builds upon earlier work in measuring offline and online social networks and contributes by looking at how Social Networks in specifically the Enterprise context could be analysed, using both absolute and relative and both quantitative and qualitative metrics. The authors underscore the great value of ESN analysis to boost such organizational practices as staffing decisions, performance management and ESN adoption and usage.

The final chapter of the book moves beyond an organizational focus to consider the potential for social knowledge management at a societal level. Its focus is the advancement and preservation of knowledge relating to endangered languages. Using a design science approach, and the case of authors Asfahaan Mirza and David Sundaram propose a solution based on SKM-based crowd-sourcing. Their 
proposed design is based on the case of Te Reo Māori (the indigenous language of New Zealand). Mirza and Sundaram's work, illustrating the benefits a specific application of the crowd-based approach to knowledge management (Newell, 2014), suggests that there may be significant untapped potential for gaining benefits from social knowledge management at levels that lie well beyond the scope of the organization.

\section{$7 \quad$ A Bright Future Ahead}

While the chapters in this book provide an overview of contemporary research of the application of social media in the field of knowledge management, the books by no means claims to provide an answer to all contemporary challenges in the field of Social Knowledge Management. This emergent area still holds much future promise for exploration and we note that each of the book chapters provides suggestions for future research in the area. Hence, this book is merely marking the start of the research journey in this promising field. As editors, we hope that this book provides a combination of inspiration and insights for both researchers and practitioners. Researchers are encouraged to continue research in this field, following up the suggestions for further research and embarking on further new directions. Practitioners are encouraged to combine critical and creative judgement with agility, building on the lessons reported on in this book while continuing to experiment with social media. We also encourage practioners to share these experiences with each other and with researchers. In particular, the crowdsourcing and sensor approaches are still emergent, and represent largely unchartered research territory. Therefore, we hope to welcome interesting research in these areas in future conferences and journals.

\section{References}

Alavi, M., \& Leidner, D. E. (2001). Review: Knowledge management and knowledge management systems: Conceptual foundations and research issues. MIS Quarterly, 25(1), 107-136.

Back, A., Von Krogh, G., Seufert, A., Enkel, E., Raimann, J., Vassiliadis, S., et al. (2005). Putting knowledge networks into action: Methodology, development, maintenance. Heidelberg: SpringerVerlag.

Barney, J. B. (1991). Firm resources and sustained competitive advantage. Journal of Management, 17(1), 99-120.

Bebensee, T., Helms, R. W., \& Spruit, M. (2011). Exploring Web 2.0 applications as a mean of bolstering up knowledge management. Electronic Journal of Knowledge Management, 9(1), $1-9$.

Behrendt, S., Richter, A., \& Riemer, K. (2014). Conceptualisation of digital traces for the identification of informal networks in enterprise social networks. In Proceedings of the 25th Australasian Conference on Information Systems (pp. 1-10). Auckland, New Zealand.

Bibbo, D., Sprehe, E., Michelich, J., \& Lee, Y. E. (2010). Employing Wiki as a Collaborative Information Repository in a Media and Entertainment Company: The NBC Universal Case. In ICIS 2010 Proceedings (p. Paper 244).

Boyd, D. M., \& Ellison, N. B. (2007). Social network sites: Definition, history, and scholarship. Journal of Computer-Mediated Communication, 13(1), 210-230. 
Chai, K., Potdar, V., \& Dillon, T. (2009). Content quality assessment related frameworks for social media. In O. Gervasi, D. Taniar, B. Murgante, A. Laganà, Y. Mun, \& M. L. Gavrilova (Eds.), Computational science and its applications-ICCSA 2009 (pp. 791-805). Heidelberg: Springer.

Chesbrough, H. W. (2003). The era of open innovation. MIT Sloan Management Review, 44(3), $35-41$.

Chua, A., \& Lam, W. (2005). Why KM projects fail: A multi-case analysis. Journal of Knowledge Management, 9(3), 6-17.

De VOC site. (n.d.). Retrieved February 19, 2016, from http://www.vocsite.nl/geschiedenis/navigatie. html.

Doerfel, S., Jäschke, R., \& Stumme, G. (2016). The role of cores in recommender benchmarking for social bookmarking systems. ACM Transactions on Intelligent Systems and Technology (TIST), 7(4), 1-33.

Du, H. S., \& Wagner, C. (2006). Weblog success: Exploring the role of technology. International Journal of Human Computer Studies, 64(9), 789-798.

Facebook. (n.d.). Facebook Stats. Retrieved May 12, 2016, from http://newsroom.fb.com/com pany-info/.

Grant, R. M. (1996). Toward a knowledge-based theory of the firm. Strategic Management Journal, $17,109-122$.

Gray, P. H. (2011). Innovation impacts of using social bookmarking systems. MIS Quarterly, 35 (3), 629-643.

Hansen, M. T., Nohria, N., \& Tierney, T. (1999). What's your strategy for managing knowledge? Harvard Business Review, 77, 106-116.

Heisig, P. (2009). Harmonisation of knowledge management-comparing $160 \mathrm{KM}$ frameworks around the globe. Journal of Knowledge Management, 13(4), 4-31.

Helms, R. W. (2007). Redesigning communities of practice using knowledge network analysis. In A. S. Kazi, L. Wohlfart, \& P. Wolf (Eds.), Hands-on knowledge co-creation and sharing: Practical methods and techniques (pp. 251-274). Stuttgart: Knowledgeboard.

Helms, R. W., \& Buysrogge, C. M. (2006). Application of knowledge network analysis to identify knowledge sharing bottlenecks at an engineering firm. In J. Ljungberg \& M. Andersson (Eds.), Proceedings of the 14th European Conference on Information Systems. Göteborg: European Conference on Information Systems.

Huysman, M., \& de Wit, D. (2004). Practices of managing knowledge sharing: Towards a second wave of knowledge management. Knowledge and Process Management, 11(2), 81-92.

Kaiser, S., Kansy, S., Mueller-Seitz, G., \& Ringlstetter, M. (2009). Weblogs for organizational knowledge sharing and creation: A comparative case study. Knowledge Management Research \& Practice, 7(2), 120-130.

Kietzmann, J. H., Hermkens, K., McCarthy, I. P., \& Silvestre, B. S. (2011). Social media? Get serious! Understanding the functional building blocks of social media. Business Horizons, 54 (3), 241-251.

Leonardi, P. M., Huysman, M., \& Steinfield, C. (2013). Enterprise social media: Definition, history, and prospects for the study of social technologies in organizations. Journal of Computer-Mediated Communication, 19(1), 1-19.

MacLeod, L., Storey, M.-A., \& Bergen, A. (2015). Code, camera, action!: How software developers document and share program knowledge using YouTube. In 2015 IEEE 23rd International Conference on Program Comprehension (pp. 104-114). IEEE Press.

Majchrzak, A., Faraj, S., Kane, G. C., \& Azad, B. (2013). The contradictory influence of social media affordances on online communal knowledge sharing. Journal of Computer-Mediated Communication, 19(1), 38-55.

Majchrzak, A., Wagner, C., \& Yates, D. (2006). Corporate wiki users: Results of a survey. In Proceedings of the 2006 International Symposium on Wikis WikiSym 06 (pp. 99-104).

Malhotra, Y. (2005). Integrating knowledge management technologies in organizational business processes: Getting real time enterprises to deliver real business performance. Journal of Knowledge Management, 9(1), 7-28. 
Maybury, M. (2002). Knowledge on demand: Knowledge and expert discovery. Journal of Universal Computer Science, 8(5), 491-505.

Millen, D. R., Feinberg, J., \& Kerr, B. (2006). Dogear: Social bookmarking in the enterprise. In Proceedings of the SIGCHI Conference on Human Factors in Computing Systems (pp. 111-120). ACM Digital Library.

Nevo, D., Benbasat, I., \& Wand, Y. (2012). Understanding technology support for organizational transactive memory: Requirements, application, and customization. Journal of Management Information Systems, 28(4), 69-98.

Newell, S. (2014). Managing knowledge and managing knowledge work: What we know and what the future holds. Journal of Information Technology, 30(1), 1-17.

Niederer, S., \& van Dijck, J. (2010). Wisdom of the crowd or technicity of content? Wikipedia as a sociotechnical system. New Media \& Society, 12, 1368-1387.

Niehaves, B., Köffer, S., \& Ortbach, K. (2012). IT consumerization-a theory and practice review. In Americas Conference on Information Systems (AMCIS) (Vol. Paper 18, pp. 1-9).

Paasivaara, M., \& Lassenius, C. (2014). Communities of practice in a large distributed agile software development organization-case ericsson. Information and Software Technology, 56, $1556-1577$

Polanyi, M. (1967). The tacit dimension. Doubleday.

Rivera-pelayo, V., Braun, S., Riss, U. V., Witschel, H. F., Hu, B., Witschel, H., et al. (2013). Building expert recommenders from email-based personal social networks. In T. Öyzer, J. Rokne, G. Wagner, \& A. H. P. Reuser (Eds.), The influence of technology on social network analysis and mining (Vol. 6, pp. 129-156). New York: Springer.

Tsai, W., \& Ghoshal, S. (1998). Social capital and value creation: The role of intrafirm networks. Academy of Management Journal, 41(4), 464-476.

von Krogh, G. (2012). How does social software change knowledge management? Toward a strategic research agenda. The Journal of Strategic Information Systems, 21(2), 154-164.

Wagner, C. (2004). Wiki: A technology for conversational knowledge management and group collaboration. Communications of the Association for Information Systems, 13, 265-289.

Wegner, D. M. (1987). Transactive memory: A contemporary analysis of the group mind. In B. Mullen \& G. R. Goethals (Eds.), Theories of group behavior (pp. 185-208). New York: Springer.

Wenger, E., \& Snyder, W. (2000). Communities of practice: The organizational frontier. Harvard Business Review, 78(1), 139-146.

Zygmunt, A., Brodka, P., Kazienko, P., \& Kozlak, J. (2012). Key person analysis in social communities within the blogosphere. Journal of Universal Computer Science, 18(4), 577-597. 